\title{
2:1 Atrioventricular Block and Severe Hypotension Due to Wild Honey Poisoning: A Case Report
}

\author{
Keshav Budhathoki ${ }^{1}$, Shyam Raj Regmi ${ }^{2}$, Sudhir Regmi ${ }^{2}$, Bishnu Mani Dhital ${ }^{2}$, \\ Anand GC ${ }^{2}$, Sabina Sedhai ${ }^{2}$ \\ ${ }^{1,2}$ Department of Cardiology, Chitwan Medical College and Teaching Hospital, Bharatpur, Chitwan, Nepal.
}

Corresponding Author: Keshav Budhathoki

\begin{abstract}
Wild Honey poisoning is caused by ingestion of wild honey obtained from the nectar of some species of Rhododendron, consuming leaves and flowers of Rhododendron found in the higher altitudes of Nepal which has traditionally been used by indigenous people of Nepal especially Himalayan belt of Nepal for its medicinal properties. The cause of poisoning is the toxin called grayanotoxin which is a naturally occurring sodium channel toxin that leads to life threatening bradycardia, hypotension and altered mental status but sometime it may present with rare life threatening atrioventricular block and cardiovascular collapse. Wild honey intoxication has widely been reported from Turkey, regions around the Black sea, Austria, Korea and some cases from Nepal. Wild honey poisoning is not the uncommon presentation to emergency department of Chitwan Medical College as it is located to central part of Nepal. We report a case of wild honey poisoning who was referred to our hospital with arrhythmia and hypotension.
\end{abstract}

Key Words: 2:1 Atrioventricular block, Grayanotoxin, Hypotension, Nepal, Wild honey.

\section{INTRODUCTION}

Honey Poisoning is caused by consumption of wild honey made from some species of rhododendron found in higher altitudes of Nepal. Wild honey is also known as mad honey. Mad honey poisoning is a well-known condition in the Black sea of Turkey. The cause of the poisoning is the toxin known as grayanotoxin found in the honey obtained from the nectar of some species of rhododendron found growing naturally in the mountainous area of Nepal. The toxin is polyhydroxylated cyclic hydrocarbon that does not contain nitrogen. ${ }^{1,2}$ This naturally occurring sodium channel toxin cause increased parasympathetic tone. Wild honey is taken as an alternative medicine for the treatment of gastritis, acid peptic disease, Hypertension, to prevent from coronary artery disease and also believed to be a sexual stimulant.

\section{CASE PRESENTATION}

A 48 years hypertensive male on regular antihypertensive medicine was referred from Gorkha Hospital located in Gorkha to our hospital who presented there with the complain of blackout followed by sudden fainting attack, 3 episodes of vomiting, profusely sweating, generalized weakness and tremor. He gives history of ingestion of wild honey (around $30 \mathrm{ml}$ that is 6 teaspoon) with a glass of alcohol for medicinal purpose while on trek to northern hilly part of Gorkha. One hour after ingestion of honey mixed alcohol, he developed above symptoms and landed to Gorkha hospital where his blood pressure 70/40mmHg, Pulse 39bpm, Spo2 94\% in room air, RR 18/min. $\mathrm{He}$ was semiconscious, pupil were bilaterally dilated and reacting to light sluggishly. ECG was taken and found to have sinus bradycardia @ $39 \mathrm{bpm}$. So, there, they resuscitated with iv atropine $0.6 \mathrm{mg}$ immediately then iv 

report.

hydrocortisone, ondansetron and parental fluids after which vital went upto BP140/90mmHg, Pulse 78bpm, Spo2 92\% and RR 12/min and referred to our hospital for further management.

On arrival to our hospital after 1 hour drive from Gorkha, he was conscious but still complains of weakness of whole body, blurring of vision. His BP was 70/50mmHg, Pulse 47bpm, Spo2 94\% and RR 14/min. On reviewing Gorkha hospital document, we found that ECG showing Sinus bradycardia at $39 \mathrm{bpm}$ with $2: 1$ atrioventricular block. Immediately ECG was done and found to have sinus bradycardia @ 47bpm with 2:1 atrioventricular block. Echo screening, hematological and biochemical parameters were within normal limit. Immediately after ECG, he was administered $0.6 \mathrm{mg}$ atropine and parenteral normal saline $(0.9 \%$ Sodium Chloride). At one minute, his maximum heart rate reached upto 86bpm. He was then admitted and monitored in ICCU, keeping in mind that if in case patient hemodynamic deteriorates, we are in ready position for insertion of temporary pacemaker. After 2 hours, his heart rate dropped to $49 \mathrm{bpm}$ though his BP maintained to $80 / 60 \mathrm{mmHg}$ without any other symptoms. So, again one ampoule of IV atropine was administered along with one ionotrope, dopamine at $5 \mathrm{mcg} / \mathrm{kg} / \mathrm{min}$. Two hours after dopamine infusion, his heart rate became $73 \mathrm{bpm}$ but his ECG showed sinus rhythm at $73 \mathrm{bpm}$ with weinkebach phenomenon and his BP increased to $100 / 70 \mathrm{mmHg}$ and dopamine infusion continued 48hours although his rhythm became normal sinus rhythm at $68 \mathrm{bpm}$ at 40 hours. On third day, the patient was clinically asymptomatic and his BP maintained to $120 / 90 \mathrm{mmHg}$, Pulse constantly at $63 \mathrm{bpm}$ regular and ECG showed normal sinus rhythm at $63 \mathrm{bpm}$ constantly. So, Parental fluid were stopped on third day and discharged without his previous antihypertensive medication and without any complication on fourth day and asking him to follow up in a few time.
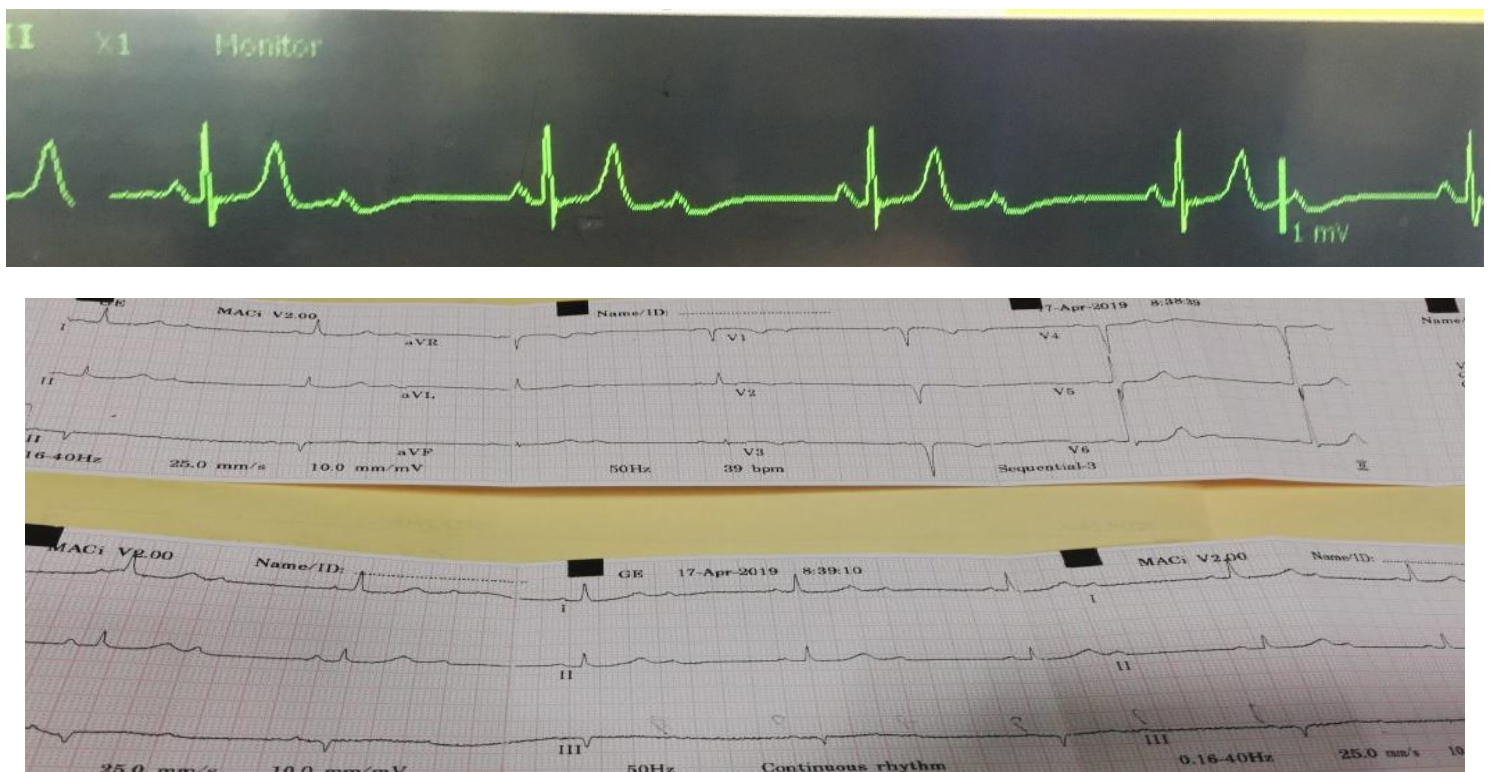

Fig 1: ECG at CMC and Gorkha hospital emergency room showing Sinus bradycardia with 2:1 AVB.

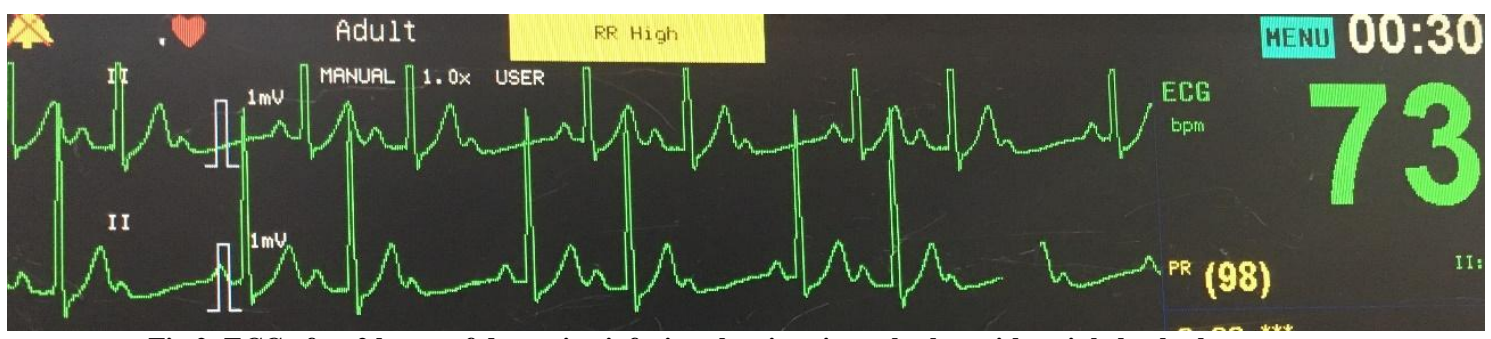

Fig 2: ECG after 2 hours of dopamine infusion showing sinus rhythm with weinkebach phenomenon. 


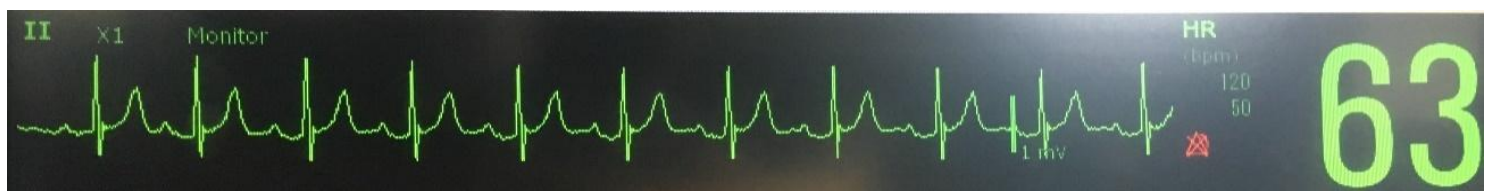

Fig 3: ECG at 40 hours of dopamine infusion showing normal sinus rhythm @ 63bpm.

\section{DISCUSSION}

Since long time in Nepal, it is believed that it can be taken as an alternative medicine for the treatment of gastritis, Peptic ulcer disease, to reduce the risk of coronary artery disease and also as a sexual stimulants. ${ }^{3}$ Honey poisoning is caused by consumption of wild honey made by bees from some species of rhododendron such as Rhododendron Luteum, R. ponticum, R. simsii. The cause of the poisoning is the toxic substance called grayanotoxin which is known to found in the nectar, leaves and flowers of rhododendron growing naturally in some hilly areas of Nepal, Turkey, Japan, Brazil and some part of North America. ${ }^{4}$ Grayanotoxin attach to sodium channels in cell membrane where it increases sodium channel permeability and inhibits repolarization thus maintaining the cell in a state of depolarization leading to weakened action potential. Ultimately, a decreased action potential brings about sinus node dysfunction. ${ }^{5}$ Atropine sulfate improves both bradycardia and respiratory rate but selective M2 muscarinic receptor antagonist only restore heart rate. This mean M2 muscarinic receptors may be involved in cardiotoxicity. ${ }^{6,7}$

The toxic effects of wild honey poisoning are rarely fatal and last for no more than 24-48 hours. Generally, it causes dizziness, weakness; sweating, nausea, vomiting, hypotension, bradycardia, syncope and atrio-ventricular block. ${ }^{2}$ Severe intoxication may lead to life threatening cardiac complications such as complete heart block, extreme hypotension and severe bradycardia. Low blood pressure responds well to the administration of fluids and sinus bradycardia and conduction block usually respond to atropine therapy. Sometime, cardiac pacing may be needed for resistant cases. The precise dose responsible for poisoning is not known. Close observation and symptomatic management are all that is necessary in honey poisoning but treating physician should be alert for sudden worsening of bradycardia and progressive conduction defect and may need of temporary pacing.

Mild poisoning is well-known to the local inhabitants and they do not generally seek for medical attention. Although honey is the widely used food products and is believed to have various medicinal benefit but the actual beneficial effect is not well documented. Honey being a commonly used food products in our daily life, more studies are required to explore for its beneficial effect, potential life threatening effects, their treatment and prevention.

\section{Acknowledgement: None}

\section{Conflict of Interest: None}

\section{Source of Funding: None}

\section{REFERENCES}

1. Gunduz A, Turedi S, Uzun H et al. Mad honey poisoning. Amer $\mathrm{J}$ Emergency Med 2006; 24:595-8.

2. yilmaz O, Eser M, Sahiner A et al. Hypotension, bradicardia and syncope caused by honey poisoning. Resuscitation 2006; 68:405-8.

3. Onat FY, Yegen BC, Lawrence R, Oktay A, Oktay S. Mad honey poisoning in man and rat. Rev Environ Health.1999; 9:3-9.

4. Hikino H, Ohizumi $\mathrm{Y}$, Kanino C, Hashimoto K, Wakasa H.Subchronic toxicity of ericaceous toxins and rhododendron leaves. Chem Pharm Bull. 1979; 27:874-879.

5. Sutlupinar N, Mat A, satganoglu Y. Poisoning by toxic honey in Turkey. Arch Toxicol.1993; 67: 148-150. 

report.

6. Ergun K, Tufekcioglu O, Aras D, Korkmaz S, Pehlivan S. A rare cause of atrioventricular block: Mad honey intoxication. Int'1 J cardiol 2005; 99:3478.

7. Onat Fy, Yegen BC, Lawrence R, Oktay A, Oktay S. Site of action of grayanotoxin in mad honey in rats. $\mathbf{J}$ Appl Toxicol 1991; 11:199-201.
How to cite this article: Budhathoki K, Regmi SR, Regmi $S$ et.al. 2:1 atrioventricular block and severe hypotension due to wild honey poisoning: a case report. International Journal of Research and Review. 2021; 8(8): 416-419. DOI:https://doi.org/10.52403/ijrr.20210857

$* * * * * *$ 